\title{
The Korean Medication Algorithm Project for Depressive Disorder 2021: Comparisons with Other Treatment Guidelines
}

\author{
Young Sup Woo', Won-Myong Bahk ${ }^{1}$, Jeong Seok Seo ${ }^{2}$, Young-Min Park ${ }^{3}$, Won Kim ${ }^{4}$, Jong-Hyun Jeong ${ }^{1}$, \\ Se-Hoon Shim ${ }^{5}$, Jung Goo Lee ${ }^{6}$, Seung-Ho Jang ${ }^{7}$, Chan-Mo Yang ${ }^{7}$, Sheng-Min Wang ${ }^{1}$, Myung Hun Jung ${ }^{8}$, \\ Hyung Mo Sung, , Il Han Choo ${ }^{10}$, Bo-Hyun Yoon ${ }^{11}$, Sang-Yeol Lee ${ }^{7}$, Duk-In Jon ${ }^{8}$, Kyung Joon Min ${ }^{2}$ \\ ${ }^{1}$ Department of Psychiatry, College of Medicine, The Catholic University of Korea, Seoul, ${ }^{2}$ Department of Psychiatry, College of Medicine, \\ Chung-Ang University, Seoul, ${ }^{3}$ Department of Psychiatry, Ilsan Paik Hospital, Inje University College of Medicine, Goyang, ${ }^{4}$ Department of \\ Psychiatry, Sanggye Paik Hospital, Inje University College of Medicine, Seoul, ${ }^{5}$ Department of Psychiatry, Soonchunhyang University Cheonan \\ Hospital, College of Medicine, Soonchunhyang University, Cheonan, ${ }^{6}$ Department of Psychiatry, Haeundae Paik Hospital, College of Medicine, \\ Inje University, Busan, 'Department of Psychiatry, Wonkwang University Hospital, School of Medicine, Wonkwang University, Iksan, \\ ${ }^{8}$ Department of Psychiatry, Hallym University Sacred Heart Hospital, Hallym University College of Medicine, Anyang, ${ }^{9}$ Department of Psychiatry, \\ Soonchunhyang University Gumi Hospital, College of Medicine, Soonchunhyang University, Gumi, ${ }^{10}$ Department of Neuropsychiatry, College \\ of Medicine, Chosun University, Department of Psychiatry, Chosun University Hospital, Gwangju, ${ }^{11}$ Department of Psychiatry, Naju National \\ Hospital, Naju, Korea
}

The Korean Medication Algorithm Project for Depressive Disorder (KMAP-DD) first was published in 2002, and has been revised four times, in 2006, 2012, 2017, and 2021. In this review, we compared recommendations from the recently revised KMAP-DD 2021 to four global clinical practice guidelines (CPGs) for depression published after 2010. The recommendations from the KMAP-DD 2021 were similar to those from other CPGs, although there were some differences. The KMAP-DD 2021 reflected social culture and the healthcare system in Korea and recent evidence about pharmacotherapy for depression, as did other recently published evidence-based guidelines. Despite some intrinsic limitations as an expert consensus-based guideline, the KMAP-DD 2021 can be helpful for Korean psychiatrists making decisions in clinical settings by complementing previously published evidence-based guidelines, especially for some clinical situations lacking evidence from rigorously designed clinical trials.

KEY WORDS: Depressive disorder; Pharmacotherapy; Consensus; Guideline; KMAP-DD 2021.

\section{INTRODUCTION}

Depression is a prevalent and debilitating psychiatric disorder characterized by frequent recurrence and significant morbidity and mortality [1]. Pharmacotherapy has been a mainstream treatment strategy for depression since the introduction of antidepressants (ADs) in the late 50s [2]. Despite substantial progress in psychopharmacology during the past several decades, a significant portion of patients with depression experiences an inade-

Received: September 24, 2021 / Accepted: October 13, 2021

Address for correspondence: Won-Myong Bahk

Department of Psychiatry, Yeouido St. Mary's Hospital,

College of Medicine, The Catholic University of Korea,

10 63-ro, Yeongdeungpo-gu, Seoul 07345, Korea

E-mail: wmbahk@catholic.ac.kr

ORCID: https://orcid.org/0000-0002-0156-2510 quate response to standard $\mathrm{AD}$ therapy, and burden from "trial-and-error" is one of the barriers to fast and effective AD treatment in clinical practice $[3,4]$. Many trials have investigated treatment strategies for people who showed insufficient treatment response, and many studies have investigated predictors of treatment outcomes, such as early treatment improvement, depressive episode characteristics, and patient characteristics [5-9]. However, it is difficult for clinicians to be acquainted with and consider al rapidly accumulating evidence when choosing the best treatment strategy for various scenarios, which increases the need for new treatment guidelines.

Many clinical practice guidelines (CPGs) for depression have been published [10-17]. The majority of these CPGs primarily is based on evidence obtained from well-de-

(c) This is an Open-Access article distributed under the terms of the Creative Commons Attribution Non-Commercial License (http://creativecommons.org/licenses/by-nc/4.0) which permits unrestricted non-commercial use, distribution, and reproduction in any medium, provided the original work is properly cited. 
signed controlled clinical trials and has great benefits. However, they might not be suitable for actual clinical practice because of various culture-specific characteristics such as depression, patient-related factors, and clinical environment, such as health care policy and prevailing medical insurance system. Thus, the Korean Medication Algorithm Project for Depressive Disorder (KMAP-DD) was developed in 2002, based on an expert consensus from Korean psychiatrists with experience treating depression [18]. Thereafter, the KMAP-DD was revised four times in 2006 [19], 2012 [20], 2017 [21], and 2021 [22]. To identify similarities and differences between KMAP-DD and other global CPGs, we compared the recommendations of the KMAP-DD with those of other CPGs starting in $2012[23,24]$. Thus, we aimed to compare the recommendations of the updated KMAP-DD 2021 with those of relatively recently published CPGs to supplement any KMAP-DD 2021 weaknesses and to direct future revisions of the Korean Medication Algorithm Project.

\section{TREATMENT GUIDELINES FOR COMPARISON}

\section{British Association for Psychopharmacology Guidelines}

The British Association for Psychopharmacology (BAP) has published a series of evidence-based guidelines for the use of drugs in psychiatric disorders, with an emphasis on producing comprehensive but concise and useable guidelines based on a review of current evidence [17]. BAP published their first guidelines in 1993 [25], and revised them in 2000 [26] and 2008 [27]. The most recent revision of the BAP guidelines (BAP 2015) [17] updates the guidelines in light of new evidence and to make a strong effort toward evidence-based recommendations only.

Canadian Network for Mood and Anxiety Treatments Clinical Guidelines for the Management of Major Depressive Disorders

The Canadian Network for Mood and Anxiety Treatments (CANMAT) and the Canadian Psychiatric Association collaborated to publish evidence-based guidelines for depression in 2001 [28-34]. These guidelines were revised in 2009 [35-40], and the most recent revised version was published in 2016 (CANMAT 2016) [1,12,41-45]. The CANMAT 2016 applied a clinically useful method that balances systematic reviews with consensus expert opinion [41].

\section{Royal Australian and New Zealand College of Psychiatrists' Clinical Practice Guidelines for Mood Disorders: Major Depression}

The Royal Australian and New Zealand College of Psychiatrists (RANZCP) developed the Mood Disorders Clinical Practice Guidelines for clinical management of mood disorders in 2015 [46], and revised them in 2020 (RANZCP 2020) [14]. The RANZCP 2020 encompasses both evidence-based and expert consensus-based recommendations (CBRs) to provide advice and guidance regarding management of mood disorder, derived from scientific evidence and supplemented by expert clinical consensus. When sufficient evidence exists, the Mood Disorder Committee formulates evidence-based recommendations according to the Australian National Health and Medical Research Council Levels of Evidence for Intervention Studies. Where this is not possible; for example, because of insufficient evidence, they develop CBRs [14].

\section{World Federation of Societies of Biological Psychiatry Guidelines for Biological Treatment of Unipolar Depressive Disorders}

The World Federation of Societies of Biological Psychiatry (WFSBP) published an evidence-based guideline in 2002 $[47,48]$. The second edition was revised and published in 2007 [49], and an updated version was published in 2013 (WFSBP 2013) [16], on acute and continuation treatment, and an update on maintenance treatment was added in 2015 [11]. The recommendations in the WFSBP guidelines were based on an initial comprehensive review of all available evidence by a systematic literature search and appraisal. The guidelines were intended for use by all physicians seeing and treating patients with these conditions [16].

\section{Korean Medication Algorithm Project for Depressive Disorder 2021}

The KMAP-DD 2021 [22] is a set of expert consensusbased guidelines. The detailed methods regarding the composition of the review committee, questionnaire preparation, data analyses, and development of treatment guidelines and algorithms for this fourth revision were similar to 


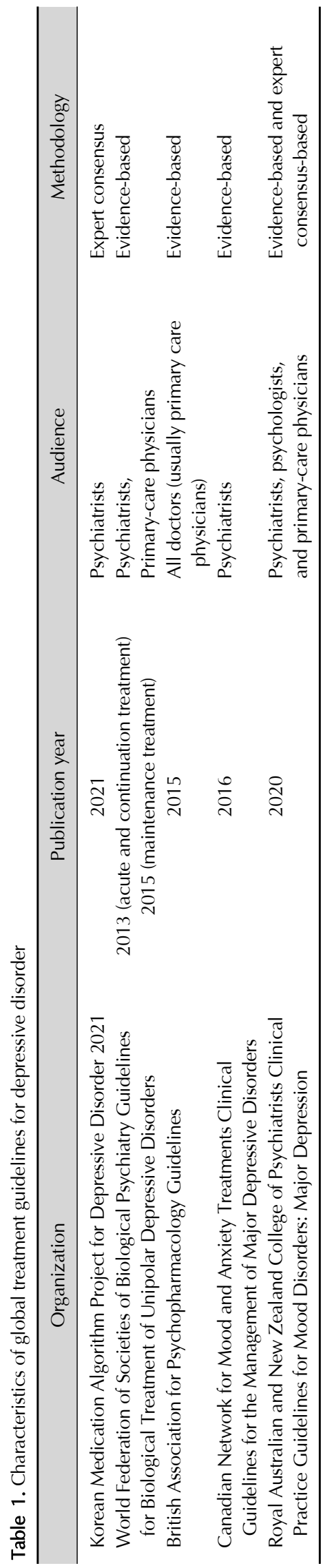

those for previous KMAP-DD studies [18,20,21]. The detailed full methods have been described [22]; the questionnaire used in the KMAP-DD 2021, is similar to that questions used to develop the KMAP-DD 2017 [21], with some modifications. The survey consists of 40 main questions with 7 parts. A 9-point scale from the RAND Corporation [50] was applied to assess the adequacy of each treatment option. Each treatment option was classified into three categories based on the lowest 95\% confidence interval of the scores: $\geq 6.5$ for first-line treatment, 3.5-6.5 for second-line, and $<3.5$ for third-line. The first-line treatment options rated as 9 by $50 \%$ or more experts were defined as the treatments of choice (TOCs). The characteristics of the above-mentioned four treatment guidelines are summarized in Table 1.

\section{COMPARISONS OF TREATMENT OPTIONS ACROSS TREATMENT GUIDELINES}

\section{Initial Treatment for Depressive Episode}

In the KMAP-DD 2021, AD monotherapy was recommended as the TOC for a mild to moderate episode and the first-line treatment for severe nonpsychotic episodes (Table 2). The combination of an AD and an atypical antipsychotic (AAP) was recommended as the first-line treatment for severe nonpsychotic episodes and the TOC for psychotic major depressive episodes (MDE). Among ADs, escitalopram was the TOC, and other selective serotonin reuptake inhibitors (SSRIs), serotonin-norepinephrine reuptake inhibitors (SNRIs) excluding milnacipran, and mirtazapine were recommended as first-line ADs for depression of all severity levels. Vortioxetine also was included in the first-line medications for nonpsychotic MDE. Among AAPs, aripiprazole was selected as the first-line treatment for nonpsychotic MD and as the TOC for psychotic depression. Quetiapine and olanzapine were recommended as first-line treatments for psychotic depression.

For mild episodes, most CPGs recommend non-pharmacological interventions such as psychoeducation, psychological treatment, or self-management as the first-line treatment except in situations where pharmacological treatment might be considered, including patient preference, previous response to pharmacotherapy, recurrent depression, and lack of response to non-pharmacological interventions (Table 2) $[12,17]$. Moreover, most CPGs 
recommend $\mathrm{AD}$ monotherapy for moderate-to-severe depressive episodes without psychotic features $[12,14,16,17]$, and augmentation with AAP is recommended for psychotic depression (Table 2). The discrepancies between KMAP-DD 2021, and other CPGs might reflect a relatively higher preference by Korean psychiatrists for AAPs for treating severe depression without psychotic features.

\section{Second-Step Treatment in Cases of Inadequate Response to Initial Treatment}

In the KMAP-DD 2021, for cases that showed no response to initial $A D$ monotherapy, augmenting with an AAP or adding or switching to another AD was recommended as the first-line treatment (Table 3). In cases of partial response to initial AD monotherapy, adding another $\mathrm{AD}$ or augmenting with an $\mathrm{AAP}$ was recommended. In cases of no response to combination $\mathrm{AD}$ and $\mathrm{AAP}$, switching the $\mathrm{AD}$ or $\mathrm{AAP}$ or adding another $\mathrm{AD}$ was recommended. When switching $A D$, another $A D$ from a different pharmacological class among SSRIs, SNRIs, mirtazapine, or vortioxetine was preferred. The one exception of an out of class switch was that switching to another SNRI from an initial SNRI was recommended as a first-line treatment. When adding another $\mathrm{AD}$, one from a different pharmacological class among SSRIs, SNRIs, mirtazapine, bupropion, vortioxetine, or agomelatine was preferred. When augmenting with AAP for psychotic depression, aripiprazole was chosen as the TOC, and quetiapine or olanzapine was recommended as first-line treatment. Aripiprazole or quetiapine was preferred as the first-line augmenting agent for non-psychotic depression.

In the WFSBP 2013 [16], a combination of two ADs (an SSRI with a presynaptic autoreceptor inhibitor) and augmentation with lithium, quetiapine, or aripiprazole were recommended when initial treatment shows an inadequate response (Table 3 ). In cases of intolerance to initial AD monotherapy, switching to a new AD with evidence of better tolerance was recommended. The BAP 2015, recommended considering both within- and between-class switching of ADs when there has been no response or intolerance and adding augmenting agents when there is a partial response (Table 3) [17]; The BAP recommends adjunctive use of quetiapine, aripiprazole, and lithium. The CANMAT 2016, recommended switching $\mathrm{AD}$ when intolerance or no response to initial treatment is an issue and to add an adjunctive medication in 


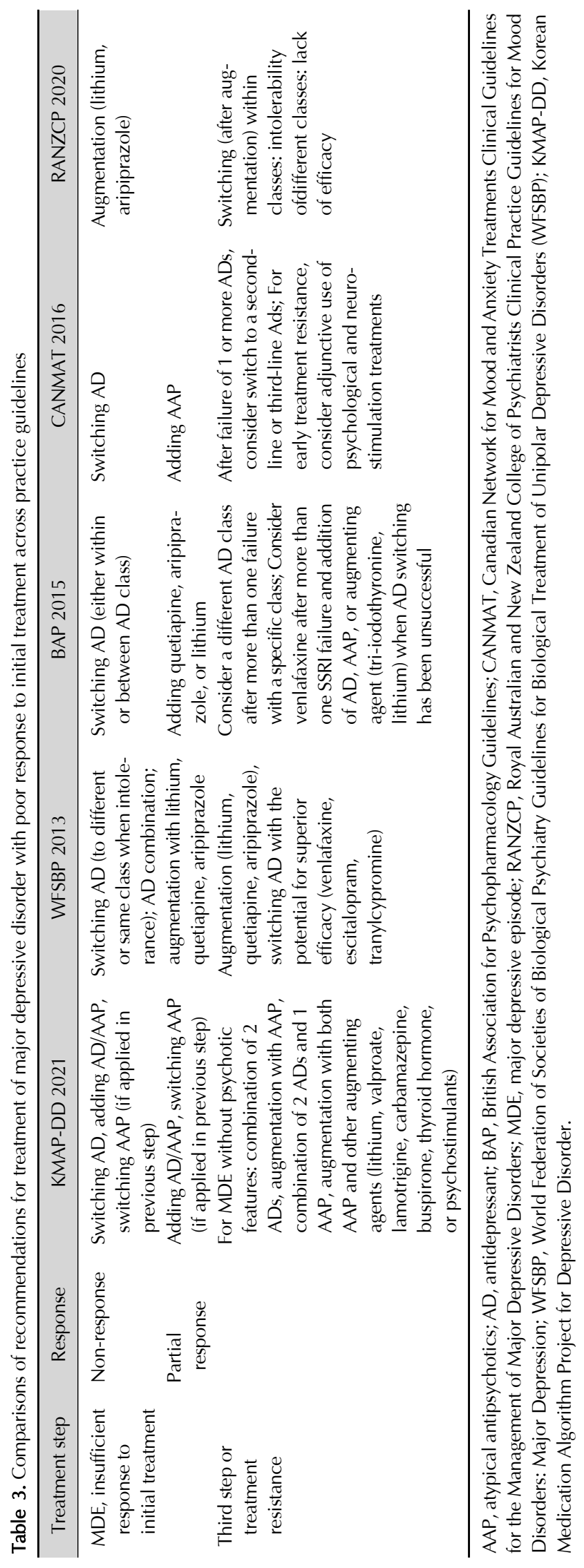


cases of partial response (Table 3) [12]. Aripiprazole, quetiapine, and risperidone were recommended as first-line adjunctive medications and brexpiprazole, lithium, modafinil, olanzapine, and triiodothyronine as second-line adjunctive medications [12]. Interestingly, RANZCP 2020, recommended only an augmenting strategy, especially with lithium or aripiprazole, as the first-line treatment where there has been insufficient response (Table 3); it stated that switching is the next alternative after augmentation [2].

These results are consistent with KMAP-DD 2021 and other guidelines in that adding augmenting agents (aripiprazole, quetiapine, and lithium) is preferred when initial treatments fail $[2,12,16,17]$.

\section{Third-Step Treatment in Cases of Inadequate Response to Second-Step Treatment}

The KMAP-DD 2021, recommends a third-step treatment for cases of inadequate response to second-step treatment (Table 3). For nonpsychotic depression, adding an AAP was the TOC, and addition of another AD was recommended as a first option when second-step treatment with $\mathrm{AD}$ monotherapy failed. For cases of nonpsychotic depression that showed inadequate response to combination of two ADs, adding an AAP or switching an $\mathrm{AD}$ to an AAP were recommended. Switching to another $\mathrm{AAP}$ or $\mathrm{AD}$, adding another $\mathrm{AD}$, or adding other augmenting agents including lithium, valproate, lamotrigine, carbamazepine, buspirone, thyroid hormone, or psychostimulants was recommended for cases of nonpsychotic depression that failed to respond to combinations of $A D$ and AAP. For psychotic depression, switching an AD or AAP into another $\mathrm{AD}$ or $\mathrm{AAP}$ and adding other augmenting agents were preferred as the first treatment in this step, and triple combinations (e.g., two $\mathrm{ADs}$ and one $\mathrm{AAP}$, one $\mathrm{AD}$ and two $\mathrm{AAPs}$, or combination of $\mathrm{AD}, \mathrm{AAP}$, and other augmenting agents) were considered for third-line treatment. Among other augmenting agents, lithium was the first option in the third step.

Most guidelines did not recommend separately a second or third step; rather, they recommended strategies for cases that failed to respond adequately to initial treatment. However, some recommendations corresponded to the third step. In the WFSBP 2013 [16], augmentation strategies recommended for second-step treatment were combinations of an SSRI with a presynaptic autoreceptor in- hibitor such as mirtazapine. The first-choice augmenting agents were lithium, quetiapine, and aripiprazole. If augmentation strategies were used as the second-step treatment, switching to a different $A D$ with the potential of superior efficacy (e.g., venlafaxine, escitalopram, and tranylcypromine) was recommended (Table 3). The BAP 2015 [17], recommended a different AD class after more than one failure with a specific class and change to venlafaxine after more than one SSRI failure (Table 3). They recommended to addition of quetiapine, aripiprazole, and lithium as first-line treatments and risperidone, olanzapine, tri-iodothyronine, and mirtazapine as second-line treatments. BAP 2015, also suggested adding bupropion, buspirone, lamotrigine, tryptophan, modafinil, and other stimulants. Moreover, these guidelines noted that it was appropriate to consider multiple combinations concurrently or to use other approaches with limited evidence in severely treatment-resistant patients. In CANMAT 2016 [12], considering a switch to second-line or third-line ADs including tricyclic antidepressants (TCAs), monoamine oxidase inhibitors (MAOIs), and quetiapine or vilazodone was recommended after one or more AD failures (Table 3). RANZCP 2020 [2] recommended switching as the third-step strategy once augmentation was trialed (Table 3). They also stated that switching AD should involve change to another class, although switching within class is acceptable if the main reason for doing so is that the initial medication was not taken as prescribed (e.g., because of side effects or poor adherence). In general, the recommendations from other guidelines are in line with those of KMAP-DD 2021; switching or adding various augmenting agents or ADs in different class, with superior efficacy but inferior safety, or with limited evidence.

\section{Pharmacological Treatment for Persistent Depressive Disorder and Each Subtype of Depression}

In the KMAP-DD 2021, AD monotherapy with escitalopram was the TOC for persistent depressive disorder (PDD). Other SSRIs including sertraline, fluoxetine, and paroxetine; and SNRIs including desvenlafaxine, venlafaxine, duloxetine, and milnacipran, vortioxetine, and mirtazapine were recommended as first-line treatments as well. For PDD, BAP 2015 [17], presented the results from a meta-analysis [51] that found a higher response rate than that of placebo for fluoxetine, paroxetine, sertraline, moclobemide, imipramine, ritanserin, amisulpride, and 
acetyl-I-carnitine. They also noted that moclobemide and amisulpride showed superiority over fluoxetine in pairwise comparisons. CANMAT 2016 [12], presented results from the same meta-analysis by Kriston et al. [51], and noted that SSRIs were similar in efficacy but superior in tolerability to TCAs in another meta-analysis of chronic depression [52].

For MDE with mixed features, KMAP-DD 2021, recommended a combination of AD with AAP or mood stabilizer (MS) as the first-line treatment. Among AAPs, aripiprazole, quetiapine, and olanzapine were included in the first line, and lithium and valproate were preferred as the first-line MS. Among ADs, SSRIs, venlafaxine, desvenlafaxine, bupropion, and mirtazapine were recommended as first-line treatments. CANMAT 2016 [12], reported that there were no trials that used the Diagnostic and Statistical Manual of Mental Disorders 5th edition criteria for mixed features; however, monotherapy with lurasidone or ziprasidone was efficacious for major depressive episodes with mixed symptoms.

For MDE with anxious distress, AD monotherapy or combination of $\mathrm{AD}$ and $\mathrm{AAP}$ was recommended as the first-line strategy. SSRIs and SNRIs except milnacipran or mirtazapine and vortioxetine were the first-line ADs. These results are consistent with the recommendations from RANZCP 2020 [2], which suggest escitalopram or venlafaxine when anxiety is the key or prominent MDD symptom. In recommendations from WFSBP 2013 [16], depressed patients with prominent anxiety symptoms or with co-morbid anxiety disorders can be treated effectively with an SSRI, venlafaxine, TCA, or MAOI. It also stated that clinicians should start patients at lower doses and increase the dose slowly for those with prominent anxiety symptoms. CANMAT 2016 [12], recommended use of an AD with efficacy in generalized anxiety disorder but also noted no differences in efficacy between SSRIs, SNRIs, and bupropion.

For MDE with melancholic features, atypical features, or with seasonal pattern, KMAP-DD 2021, recommended SSRIs and SNRIs except milnacipran or vortioxetine as a first-line AD. Escitalopram was the TOC for MDE with melancholic features. Mirtazapine was the first line for melancholic and seasonal depression and the second line for atypical depression. Bupropion was included in the recommended first-line ADs for MDE with atypical features and seasonal pattern but is recommended as the sec- ond line for MDE with melancholic features. Milnacipran can be used as the first-line treatment for melancholic or atypical depression but is considered a second-line treatment for seasonal depression. Agomelatine was the firstline AD for MDE with atypical features and second-line AD for melancholic or seasonal depression.

While RANZCP 2020 [2], recommended use of amitriptyline or venlafaxine for melancholia, other CPGs did not provide clear recommendations for pharmacological treatment of melancholic depression. CANMAT 2016 [12], noted that no specific ADs have demonstrated superiority. BAP 2015 [17], concluded that it is insufficient to guide first-line $A D$ choices, although a few retrospective studies suggested that TCAs are more effective than SSRIs for melancholic depression. WFSBP 2013 [16], presented conflicting results and did not offer any recommendations: paroxetine [53], venlafaxine [54], and moclobemide [55] were more effective than placebo and as effective as TCAs in some studies, but TCAs and SNRIs were more effective than SSRIs in other studies $[56,57]$.

For atypical features, the KMAP-DD 2021, recommends various SSRIs and SNRIs as first-line treatments, which is different from other CPGs. While CANMAT 2016 [12] stated that no specific ADs have shown superiority, WFSBP 2013 [16], suggested that irreversible MAOIs such as phenelzine and tranylcypromine could be more beneficial for patients with atypical features. BAP 2015 [17], also suggested an advantage of MAOls over TCAs in atypical depression. Moreover, BAP 2015 [17], noted that MAOIs (e.g., moclobemide) could be effective for seasonal depression, as could sertraline, fluoxetine, and bupropion. However, MAOls were excluded from the choices in the KMAP-DD 2021, survey because preference for MAOIs had been low in previous KMAP-DDs, and MAOI use has declined due to side effects, drug - drug interactions, and difficulty of following a low-tyramine diet [58].

\section{Pharmacological Treatment for Child and Adolescent Depression}

The KMAP-DD 2021, does not suggest a first-line treatment for disruptive mood dysregulation disorder (DMDD). Monotherapy with $\mathrm{AD}$ or AAP, or combination of AAP and $\mathrm{AD}$ was recommended as second-line strategy. KMAP-DD 2021, recommended escitalopram, fluoxetine, aripiprazole, or risperidone for DMDD. Valproate also was recommended for male patients. There are no guide- 
lines for recommendations for DMDD; thus, we cannot compare directly the KMAP-DD 2021, recommendations with those of other CPGs. In clinical trials for DMDD, lithium was not beneficial compared with placebo for patients with severe mood dysregulation [59], but treatment with a psychostimulant alone [60] or combined with aripiprazole [61] could be effective for DMDD. Given the dearth of evidence regarding treatment strategies for DMDD, the CBRs in the KMAP-DD 2021, could be valuable. However, they should be further tested for applicability in clinical practice.

KMAP-DD 2021 recommended AD monotherapy as the TOC for mild-to-moderate depression in children, and it was the first-line treatment strategy for mild-to-moderate depression in adolescents. AD monotherapy and combination with AAP were the first-line strategies for children and adolescents with severe non-psychotic depression, and combination of AD with AAP was the TOC for severe psychotic depression. Among ADs, escitalopram was the TOC and fluoxetine was the first-line treatment for children and adolescents with mild-to-moderate depression. Sertraline was the first-line AD for adolescents with mild-to-moderate depression. For children and adolescents with psychotic or severe non-psychotic depression, escitalopram, fluoxetine, and sertraline were preferred. Among AAPs, aripiprazole was the TOC for children and adolescents with psychotic depression, and risperidone and quetiapine were the first-line treatment for children with psychotic depression. These guidelines, which mainly recommend monotherapy with escitalopram, fluoxetine, or sertraline, were similar those from CANMAT 2016 [45], which recommended fluoxetine, escitalopram, sertraline, and citalopram as the best second-line ADs. The preference for escitalopram over fluoxetine in KMAP-DD 2021, reflects recent evidence of the superior efficacy of escitalopram for improving children and adolescent function and symptoms compared with placebo [62] and its relative safety and tolerability $[62,63]$.

However, CANMAT 2016 [45], recommended cognitive-behavioral therapy (CBT) or interpersonal therapy (IPT) as first-line treatment for major depression among children and youth. Furthermore, BAP 2015 [17], recommended that ADs are not a first-line treatment for major depression in children and adolescents, and AD treatment should be considered only when there has been a partial or no response to other treatments such as CBT or IPT, where depression is severe, or when there is a history of moderate-to-severe recurrent depression. In recent CPGs for depression in children and young people [64], psychological therapy including CBT, non-directive supportive therapy, and IPT was recommended for mild depression in children and adolescents. For moderate-to-severe depression, the NICE guidelines [64] recommended psychological therapy initially; combined treatment of fluoxetine and psychological therapy could be considered as initial treatment for moderate-to-severe depression in young people (12-18 years). Sertraline and citalopram were limited to situations when patients and parents/caregivers have been informed fully, the depression is sufficiently severe, and there has been a reasonable effort to try combination treatment of fluoxetine and psychological therapy [64].

Caution should be paid to AD use in children and adolescents, because ADs can be associated with increased risk of suicide and mood swings in young people $[65,66]$. Although psychological intervention should be the first step for mild depressive episodes in pediatric depression patients based on risk-benefit evaluation, cautious pharmacotherapy could be considered for more severe episodes or when initial psychosocial intervention for mild depressive episodes failed.

\section{Pharmacological Treatment for Geriatric Depression}

Monotherapy with AD was the TOC for mild-to-moderate geriatric depression in KMAP-DD 2021. The combination of $A D$ and $A A P$ and monotherapy with $A D$ were the first-line treatments for severe non-psychotic depression, and the combination of $\mathrm{AD}$ and AAP was recommended as first-line treatment for patients with severe psychotic episodes. Among ADs, escitalopram was preferred, and SSRIs, SNRIs, vortioxetine, and mirtazapine were recommended as first-line treatments; paroxetine was included in the first line only for severe episodes. These recommendations are similar to those from WFSBP 2013 [16], which recommended SSRIs and other newer ADs due to the higher risk of adverse effects with TCAs, such as cardiovascular and anticholinergic effects. They also recommended that old age not limit full use of the whole spectrum of AD options. However, CANMAT 2016 [45], recommended escitalopram, which was recommended as the TOC by KMAP-DD 2021, based on level-2 evidence, along with bupropion, desvenlafaxine, sertraline, 
venlafaxine, and vortioxetine, although they were included as first-line ADs. CANMAT 2016 [45], recommended duloxetine, mirtazapine, and nortriptyline as first-line treatments with level-1 evidence. Nevertheless, CANMAT 2016 [45], also noted that escitalopram and citalopram generally are considered by clinicians to be first-line treatments for late-life depression due to their tolerability and fewer drug interactions, although none of the RCTs involving these drugs demonstrated superiority over placebo in the elderly. Thus, CANMAT 2016 [45], suggested that treatment recommendations for late-life depression must be evidence-informed rather than evidence-based.

\section{Pharmacological Treatment for Depression in Women}

KMAP-DD 2021 recommended AD monotherapy with fluoxetine, escitalopram, sertraline, paroxetine, desvenlafaxine, or venlafaxine as the first-line treatment strategy for premenstrual dysphoric disorder.

For MDD in pregnant women, AD monotherapy was recommended as the first-line treatment for mild-to-moderate and severe non-psychotic depression in KMAP-DD 2021. For severe psychotic depression during pregnancy, combination of AD and AAP or electroconvulsive therapy (ECT) was recommended. In the WFSBP 2013 [16], ECT was recommended as the first-line strategy, particularly during the first trimester. RANZCP 2020 [2], also suggested that ECT is safe during pregnancy and can, in some instances, be the preferred option. CANMAT 2016 [45], recommended CBT and IPT as the first-line therapy for mild-to-moderate depression and ADs including citalopram, escitalopram, and sertraline as the second-line treatment option. For severe depression during pregnancy, CANMAT 2016 [45], recommended pharmacotherapy with citalopram, escitalopram, and sertraline as the first-line treatment, either alone or in combination with CBT or IPT. The remaining SSRIs except paroxetine, newer-generation ADs, and TCAs were recommended as second-line treatments for severe depression; and ECT also could be considered.

For postpartum depression, KMAP-DD 2021, recommended AD monotherapy and combination of $A D$ with AAP as first-line strategies for mild-to-moderate episodes. Combination of $\mathrm{AD}$ with $\mathrm{AAP}$ was recommended as first-line treatment for severe non-psychotic episodes and as TOC for severe psychotic episodes. In WFSBP 2013
[16], SSRIs were superior to general supportive care. Based on level-1 evidence, CANMAT 2016 [45], recommended CBT and IPT as first-line treatment for mild-tomoderate postpartum depression during breastfeeding. CANMAT 2016, also recommended citalopram, escitalopram, sertraline, and a combination of SSRI and CBT or IPT as second-line treatments with level-2 evidence. Pharmacotherapy with citalopram, escitalopram, and sertraline was the first-line option for severe postpartum depression in CANMAT 2016 [45], which also concluded that ECT could be considered as a first-line treatment for severe depression, especially among patients with psychosis.

\section{Choosing Antidepressants for Specific Situations}

KMAP-DD 2021, recommended choice of AD based on frequent adverse effects and tolerability issues, wherein bupropion, mirtazapine, and vortioxetine were recommended for sexual dysfunction, and bupropion, fluoxetine, and tianeptine were recommended for sedation/ somnolence. When patients were concerned about weight gain, bupropion, fluoxetine, and vortioxetine were recommended. Mirtazapine, paroxetine, and TCAs were preferred for concerns about sleep disturbance/insomnia. For gastrointestinal trouble such as nausea/vomiting, mirtazapine, tianeptine, and bupropion were recommended. Escitalopram, agomelatine, and vortioxetine were recommended for those concerned about anticholinergic side effects. For patients with orthostatic hypotension, bupropion, escitalopram, and mirtazapine were recommended by KMAP-DD 2021. These recommendations were not discordant with those of other CPGs. BAP 2015 [17], recommended sildenafil or tadalafil for use in cases of erectile dysfunction and bupropion for sexual dysfunction in men and bupropion or sildenafil for sexual dysfunction in women. CANMAT 2016 [12], also reported that agomelatine, bupropion, mirtazapine, vilazodone, and vortioxetine had lower risk of sexual side effects, and that escitalopram and paroxetine had higher risk compared with other ADs. WFSBP 2013 [16] and RANCP 2020 [2] also reported that the risk of sexual dysfunction was lower with bupropion, agomelatine, and mirtazapine. Similar to KMAP-DD 2021, RANZCP 2020 [2], and BAP 2015 [17], recommended SSRIs, SNRIs, bupropion, and vortioxetine when sedation or somnolence was a concern. SSRIs, SNRIs, bupropion, agomelatine, and vortioxetine were recommended by RANZCP 2020 [2], and BAP 2015 [17], 
when weight gain was the main concern. For sleep disturbance, RANZCP 2020, and CANMAT 2016 [2], recommended agomelatine and mirtazapine [12]. SSRIs, SNRIs, bupropion, mirtazapine, agomelatine, or vortioxetine was suggested by BAP 2015 [17], when anticholinergic adverse effects or orthostatic hypotension was a concern.

Use of ADs for suicidal depressed patients has been a significant and controversial issue for two decades. WFSBP 2013 [16], noted that most ADs have not demonstrated efficacy in suicidal patients, and a meta-analysis showed an increase in suicidal thoughts and attempts in children and adolescents. Thus, WFSBP 2013, recommended that physicians prescribe a limited supply of potentially lethal ADs such as TCA or irreversible MAOIs, and that the chosen $\mathrm{AD}$ is relatively safe in case of an overdose.

Regarding comorbid conditions, KMAP-DD 2021 recommended escitalopram, sertraline, and bupropion for patients with diabetes mellitus; escitalopram, sertraline, and fluoxetine for patients with thyroid disease; escitalopram, sertraline, and tianeptine for liver disease; escitalopram, sertraline, and tianeptine for patients with renal disease; escitalopram, sertraline, and tianeptine for patients with hypertension; escitalopram, sertraline, and tianeptine for patients with cardiovascular illness; escitalopram, sertraline, and tianeptine for patients with seizure disorders; escitalopram, sertraline, and bupropion for patients with parkinsonism; sertraline, escitalopram, and fluoxetine for patients with arrhythmia; and duloxetine, milnacipran, and venlafaxine for patients with chronic pain. There are not many discrepancies between KMAP-DD 2021, recommendations and other CPGs. WFSBP 2013, and BAP $2015[16,17]$, reported that agomelatine is contraindicated for patients with hepatic impairment, and caution is recommended for venlafaxine in hypertensive patients. For patients with cardiovascular disease, RANZCP 2020 [2], recommended fluoxetine, sertraline, vortioxetine, agomelatine, and escitalopram, and WFSBP 2013 [16] recommended SSRIs, which cause fewer cardiovascular toxicities. For patients with arrhythmia, WFSBP 2013 [16], recommended not using tianeptine or TCAs including amitriptyline, clomipramine, imipramine, and nortriptyline due to the risk of conduction delays. BAP 2015 [17], noted that recent evidence suggests the risk of dosedependent prolongation of the QT interval with escitalo- pram and citalopram. However, they also noted that concerns about QTc alone should not prevent effective use of citalopram and escitalopram in patients for whom these drugs are indicated. In addition, other ADs can increase the QTc interval, and this issue is not unique to citalopram/escitalopram.

\section{Non-pharmacological Biological Treatments}

\section{Electroconvulsive therapy}

KMAP-DD 2021, recommended ECT as the first-line treatment for patients with urgent suicidal risk, pregnant patients with severe episodes, and pregnant patients with moderate episodes who were non-responsive to pharmacotherapy. These results were consistent with recommendations from WFSBP 2013 [16], which recommended ECT as the first-line treatment for severe major depression with psychotic features or psychomotor retardation, treatment-resistant major depression, and situations when rapid depression relief is required (e.g., severe suicidality or medication contraindications such as pregnancy). BAP 2015 [17], reported that ECT is more effective than AD treatment, particularly in severe depression (including psychotic depression) cases and treatment-resistant patients. CANMAT 2016 [43], recommended ECT as a second-line treatment, but as the first-line treatment for patients with acute suicidal ideation, psychotic features, treatment-resistant depression with level-1 evidence, repeat medication intolerance, catatonic features, prior favorable response to ECT, rapidly deteriorating physical status, and during pregnancy with level-3 evidence. RANZCP 2020 [2], concluded that bifrontal or bitemporal ECT is necessary in some instances, including clear features of melancholic depression such as psychomotor retardation and psychotic features, mood-congruent delusions, and hallucinations. ECT also was recommended as first-line treatment for catatonia in the context of a mood disorder and can be administered as the preferred option in pregnancy and with urgency including inanition and dehydration.

\section{Repetitive transcranial magnetic stimulation}

WFSBP 2013 [16], and BAP 2015 [17], did not recommend repetitive transcranial magnetic stimulation (rTMS) use in depression due to insufficient evidence and uncertainty regarding the optimum treatment parameters for 
clinical efficacy. However, KMAP-DD 2021, recommended rTMS as a first-line treatment for pregnant patients with severe MDD. This recommendation was in line with recent evidence that non-invasive neurostimulation including rTMS could be an effective and feasible alternative treatment for antenatal depression $[67,68]$ and MDD patients with specific psychiatric comorbidities [69]. Moreover, CANMAT 2016, considers rTMS a first-line treatment for MDD patients who have failed at least one AD treatment [43], while KMAP-DD 2021, recommended rTMS as the second-line treatment.

\section{CONCLUSION}

In this review, we compared the recommendations from KMAP-DD 2021, to those of other CPGs. KMAP-DD 2021, is an expert-consensus guideline, while other CPGs are evidence-based. Hence, although the KMAP-DD 2021 recommendations were similar across guidelines, there were some differences in details. Korean experts needed rapid antidepressant effects, which may be due to cultural or ethnic differences, and this was reflected in the preference for AAPs for non-psychotic depression and for combination and augmentation in relatively early-stage treatments. Although KMAP-DD 2021, has some limitations as a set of expert-consensus guidelines, its strengths are its recommendations for various situations, such as PDD, MDE with mixed features, melancholic depression with atypical features, depression with seasonal pattern, and non-psychological medical illness, for which strictly designed clinical trials cannot draw evidence or were not performed sufficiently. Considering these advantages, KMAP-DD 2021, provides valuable information to Korean clinicians for making decisions in various clinical situations by complementing other evidence-based guidelines.

\section{- Funding}

This study was supported by the Korean Society for Affective Disorders and the Korean College of Neuropsychopharmacology. This research did not receive any specific grant from funding agencies in the commercial sector.

\section{- Conflicts of Interest}

No potential conflict of interest relevant to this article was reported.

\section{Author Contributions}

Conceptualization: Young Sup Woo, Won-Myong Bahk. Study design and data collection: Young Sup Woo, Won-Myong Bahk, Jeong Seok Seo, Young-Min Park, Won Kim, Jong-Hyun Jeong, Se-Hoon Shim, Jung Goo Lee, Seung-Ho Jang, Chan-Mo Yang, Sheng-Min Wang, Myung Hun Jung, Hyung Mo Sung, IL Han Choo, Bo-Hyun Yoon, Sang-Yeol Lee, Duk-In Jon, Kyung Joon Min. Guideline review: Young Sup Woo, Jeong Seok Seo, Won-Myong Bahk, Young-Min Park, Won Kim, Jong-Hyun Jeong, Se-Hoon Shim, Jung Goo Lee, Seung-Ho Jang. Data analysis and interpretation: Jeong Seok Seo, Won-Myong Bahk, Young Sup Woo, Young-Min Park, Won Kim, Jong-Hyun Jeong, Se-Hoon Shim, Jung Goo Lee, Seung-Ho Jang. Funding acquisition: Won-Myong Bahk, Jeong Seok Seo. Draft manuscript preparation: Young Sup Woo. All authors reviewed the results and approved the final version of the manuscript.

\section{ORCID}

Young Sup Woo https://orcid.org/0000-0002-0961-838X

Won-Myong Bahk https://orcid.org/0000-0002-0156-2510 Jeong Seok Seo https://orcid.org/0000-0002-4880-3684 Young-Min Park https://orcid.org/0000-0002-4993-1426 Won Kim https://orcid.org/0000-0002-5478-7350 Jong-Hyun Jeong https://orcid.org/0000-0003-3570-7607 Se-Hoon Shim https://orcid.org/0000-0002-3137-6591 Jung Goo Lee https://orcid.org/0000-0003-3393-2667 Seung-Ho Jang https://orcid.org/0000-0002-3479-0552 Chan-Mo Yang https://orcid.org/0000-0002-4959-7595 Sheng-Min Wang https://orcid.org/0000-0003-2521-1413 Myung Hun Jung https://orcid.org/0000-0003-2393-3930 Hyung Mo Sung https://orcid.org/0000-0002-2396-3358 IL Han Choo https://orcid.org/0000-0001-6547-9735 Bo-Hyun Yoon https://orcid.org/0000-0002-3882-7930 Sang-Yeol Lee https://orcid.org/0000-0003-1828-9992 Duk-In Jon https://orcid.org/0000-0002-1565-7940 Kyung Joon Min ～https://orcid.org/0000-0001-7037-8904

\section{REFERENCES}

1. Lam RW, Mclntosh D, Wang J, Enns MW, Kolivakis T, Michalak EE, et al. Canadian Network for Mood and Anxiety Treatments (CANMAT) 2016 clinical guidelines for the management of adults with major depressive disorder: section 1. Disease burden and principles of care. Can J Psychiatry 2016;61:510-523.

2. Malhi GS, Bell E, Singh AB, Bassett D, Berk M, Boyce P, et al. 
The 2020 Royal Australian and New Zealand College of Psychiatrists clinical practice guidelines for mood disorders: major depression summary. Bipolar Disord 2020;22:788-804.

3. Rush AJ, Trivedi MH, Wisniewski SR, Nierenberg AA, Stewart JW, Warden D, et al. Acute and longer-term outcomes in depressed outpatients requiring one or several treatment steps: a STAR*D report. Am J Psychiatry 2006;163:1905-1917.

4. Lee KH, Bahk WM, Lee SJ, Serretti A, Pae CU. A practical utility and benefit of pharmacogenetic-based antidepressant treatment strategy for major depressive disorder patients with difficult-to-treat. Clin Psychopharmacol Neurosci 2021;19:160165.

5. Sueki A, Suzuki E, Takahashi H, Ishigooka J. Does early improvement in depressive symptoms predict subsequent remission in patients with depression who are treated with duloxetine? Neuropsychiatr Dis Treat 2016;12:1269-1273.

6. Fabbri C, Serretti A. How to utilize clinical and genetic information for personalized treatment of major depressive disorder: step by step strategic approach. Clin Psychopharmacol Neurosci 2020;18:484-492.

7. Woo YS, Rosenblat JD, Kakar R, Bahk WM, Mclntyre RS. Cognitive deficits as a mediator of poor occupational function in remitted major depressive disorder patients. Clin Psychopharmacol Neurosci 2016;14:1-16.

8. Woo YS, Seo HJ, McIntyre RS, Bahk WM. Obesity and its potential effects on antidepressant treatment outcomes in patients with depressive disorders: a literature review. Int J Mol Sci 2016;17:80.

9. Mosiołek A, Pięta A, Jakima S, Zborowska N, Mosiołek J, Szulc A. Effects of antidepressant treatment on peripheral biomarkers in patients with major depressive disorder (MDD). J Clin Med 2021;10:1706.

10. American Psychiatric Association. Practice guideline for the treatment of patients with major depressive disorder. 3rd ed. Washington, D.C.:American Psychiatric Association;2009.

11. Bauer M, Severus E, Köhler S, Whybrow PC, Angst J, Möller HJ. World Federation of Societies of Biological Psychiatry (WFSBP) guidelines for biological treatment of unipolar depressive disorders. part 2: maintenance treatment of major depressive disorder-update 2015. World J Biol Psychiatry 2015; 16:76-95.

12. Kennedy SH, Lam RW, Mclntyre RS, Tourjman SV, Bhat V, Blier P, et al. Canadian Network for Mood and Anxiety Treatments (CANMAT) 2016 clinical guidelines for the management of adults with major depressive disorder: section 3. Pharmacological treatments. Can J Psychiatry 2016;61:540560.

13. National Collaborating Centre for Mental Health (Great Britain). Depression: the treatment and management of depression in adults. National Collaborating Centre for Mental Health;2010.

14. Malhi GS, Bell E, Bassett D, Boyce P, Bryant R, Hazell P, et al. The 2020 Royal Australian and New Zealand College of Psychiatrists clinical practice guidelines for mood disorders.
Aust NZ J Psychiatry 2021;55:7-117.

15. Suehs B, Argo T, Bendele S, Crismon ML, Trivedi MH, Kurian B. Texas medication algorithm project procedural manual. Major depressive disorder algorithms. Texas:Texas Department of State Health Services;2008.

16. Bauer M, Pfennig A, Severus E, Whybrow PC, Angst J, Möller HJ. World Federation of Societies of Biological Psychiatry (WFSBP) guidelines for biological treatment of unipolar depressive disorders, part 1: update 2013 on the acute and continuation treatment of unipolar depressive disorders. World J Biol Psychiatry 2013;14:334-385.

17. Cleare A, Pariante CM, Young AH, Anderson IM, Christmas D, Cowen PJ, et al. Evidence-based guidelines for treating depressive disorders with antidepressants: a revision of the 2008 British Association for Psychopharmacology guidelines. J Psychopharmacol 2015;29:459-525.

18. Lee MS, Lim SW, Cha JH, Chung SK, Kim KS, Kasper S, et al. The Korean Medication Algorithm for Major Depressive Disorder (KMA-MDD): report of the Korean Society of Depressive and Bipolar Disorders. Int I Psychiatry Clin Pract 2006;10:186194.

19. Seo JS, Min KJ, Kim W, Seok JH, Bahk WM, Song HC, et al. Korean Medication Algorithm for Depressive Disorder 2006 (I). J Korean Neuropsychiatr Assoc 2007;46:453-460.

20. Seo JS, Song HR, Lee HB, Park YM, Hong JW, Kim W, et al. The Korean Medication Algorithm for Depressive Disorder: second revision. J Affect Disord 2014; 167:312-321.

21. Seo JS, Bahk WM, Wang HR, Woo YS, Park YM, Jeong JH, et al. Korean Medication Algorithm for Depressive Disorders 2017: third revision. Clin Psychopharmacol Neurosci 2018; 16:67-87.

22. Seo JS, Bahk WM, Woo YS, Park YM, Kim W, Jeong JH, et al. Korean Medication Algorithm for Depressive Disorder 2021, fourth revision: an executive summary. Clin Psychopharmacol Neurosci 2021;19:751-772.

23. Wang HR, Bahk WM, Park YM, Lee HB, Song HR, Jeong JH, et al. Korean Medication Algorithm for Depressive Disorder: comparisons with other treatment guidelines. Psychiatry Investig 2014;11:1-11.

24. Wang HR, Bahk WM, Seo JS, Woo YS, Park YM, Jeong JH, et al. Korean Medication Algorithm for Depressive Disorder: comparisons with other treatment guidelines. Clin Psychopharmacol Neurosci 2017;15:199-209.

25. Montgomery SA, Bebbington $P$, Cowen $P$, Deakin W, Freeling $\mathrm{P}$, Hallstrom C, et al. Guidelines for treating depressive illness with antidepressants: a statement from the British Association for Psychopharmacology. J Psychopharmacol 1993; 7(1 Suppl): 19-23.

26. Anderson IM, Nutt DJ, Deakin JF. Evidence-based guidelines for treating depressive disorders with antidepressants: a revision of the 1993 British Association for Psychopharmacology guidelines. British Association for Psychopharmacology. I Psychopharmacol 2000;14:3-20. 
27. Anderson IM, Ferrier IN, Baldwin RC, Cowen PJ, Howard L, Lewis $\mathrm{G}$, et al. Evidence-based guidelines for treating depressive disorders with antidepressants: a revision of the 2000 British Association for Psychopharmacology guidelines. I Psychopharmacol 2008;22:343-396.

28. Parikh SV, Lam RW; CANMAT Depression Work Group. Clinical guidelines for the treatment of depressive disorders. I. Definitions, prevalence, and health burden. Can J Psychiatry 2001;46 Suppl 1:13S-20S.

29. Reesal RT, Lam RW; CANMAT Depression Work Group. Clinical guidelines for the treatment of depressive disorders. 11. Principles of management. Can J Psychiatry 2001;46 Supp/ 1:21S-28S.

30. Segal ZV, Whitney DK, Lam RW; CANMAT Depression Work Group. Clinical guidelines for the treatment of depressive disorders. III. Psychotherapy. Can J Psychiatry 2001;46 Suppl 1:29S-37S.

31. Kennedy SH, Lam RW, Cohen NL, Ravindran AV; CANMAT Depression Work Group. Clinical guidelines for the treatment of depressive disorders. IV. Medications and other biological treatments. Can J Psychiatry 2001;46 Supp/ 1:38S-58S.

32. Segal ZV, Kennedy SH, Cohen NL; CANMAT Depression Work Group. Clinical guidelines for the treatment of depressive disorders. V. Combining psychotherapy and pharmacotherapy. Can J Psychiatry 2001;46 Supp/ 1:59S-62S.

33. Thorpe L, Whitney DK, Kutcher SP, Kennedy SH; CANMAT Depression Work Group. Clinical guidelines for the treatment of depressive disorders. VI. Special populations. Can J Psychiatry 2001;46 Supp/ 1:63S-76S.

34. Enns MW, Swenson JR, Mclntyre RS, Swinson RP, Kennedy $\mathrm{SH}$; CANMAT Depression Work Group. Clinical guidelines for the treatment of depressive disorders. VII. Comorbidity. Can J Psychiatry 2001;46 Suppl 1:77S-90S.

35. Patten SB, Kennedy SH, Lam RW, O’Donovan C, Filteau MJ, Parikh SV, et al. Canadian Network for Mood and Anxiety Treatments (CANMAT) clinical guidelines for the management of major depressive disorder in adults. I. Classification, burden and principles of management. J Affect Disord 2009; 117 Suppl 1:S5-S14.

36. Parikh SV, Segal ZV, Grigoriadis S, Ravindran AV, Kennedy SH, Lam RW, et al. Canadian Network for Mood and Anxiety Treatments (CANMAT) clinical guidelines for the management of major depressive disorder in adults. II. Psychotherapy alone or in combination with antidepressant medication. J Affect Disord 2009;117 Supp/ 1:S15-S25.

37. Lam RW, Kennedy SH, Grigoriadis S, Mclntyre RS, Milev R, Ramasubbu R, et al. Canadian Network for Mood and Anxiety Treatments (CANMAT) clinical guidelines for the management of major depressive disorder in adults. III. Pharmacotherapy. J Affect Disord 2009;117 Supp/ 1:S26-S43.

38. Kennedy SH, Lam RW, Parikh SV, Patten SB, Ravindran AV. Canadian Network for Mood and Anxiety Treatments (CANMAT) clinical guidelines for the management of major depressive disorder in adults. Introduction. I Affect Disord 2009;117 Supp/ 1:S1-S2.

39. Kennedy SH, Milev R, Giacobbe P, Ramasubbu R, Lam RW, Parikh SV, et al. Canadian Network for Mood and Anxiety Treatments (CANMAT) clinical guidelines for the management of major depressive disorder in adults. IV. Neurostimulation therapies. J Affect Disord 2009;117 Supp/ 1:S44-S53.

40. Ravindran AV, Lam RW, Filteau MJ, Lespérance F, Kennedy $\mathrm{SH}$, Parikh SV, et al. Canadian Network for Mood and Anxiety Treatments (CANMAT) clinical guidelines for the management of major depressive disorder in adults. V. Complementary and alternative medicine treatments. J Affect Disord 2009;117 Supp/ 1:S54-S64.

41. Lam RW, Kennedy SH, Parikh SV, MacQueen GM, Milev RV, Ravindran AV. Canadian Network for Mood and Anxiety Treatments (CANMAT) 2016 clinical guidelines for the management of adults with major depressive disorder: introduction and methods. Can J Psychiatry 2016;61:506-509.

42. Parikh SV, Quilty LC, Ravitz P, Rosenbluth M, Pavlova B, Grigoriadis S, et al. Canadian Network for Mood and Anxiety Treatments (CANMAT) 2016 clinical guidelines for the management of adults with major depressive disorder: section 2. Psychological treatments. Can J Psychiatry 2016;61:524-539.

43. Milev RV, Giacobbe P, Kennedy SH, Blumberger DM, Daskalakis ZJ, Downar J, et al. Canadian Network for Mood and Anxiety Treatments (CANMAT) 2016 clinical guidelines for the management of adults with major depressive disorder: section 4. Neurostimulation treatments. Can J Psychiatry 2016;61:561-575.

44. Ravindran AV, Balneaves LG, Faulkner G, Ortiz A, McIntosh D, Morehouse RL, et al. Canadian Network for Mood and Anxiety Treatments (CANMAT) 2016 clinical guidelines for the management of adults with major depressive disorder: section 5. Complementary and alternative medicine treatments. Can J Psychiatry 2016;61:576-587.

45. MacQueen GM, Frey BN, Ismail Z, Jaworska N, Steiner M, Lieshout RJ, et al. Canadian Network for Mood and Anxiety Treatments (CANMAT) 2016 clinical guidelines for the management of adults with major depressive disorder: section 6. Special populations: youth, women, and the elderly. Can J Psychiatry 2016;61:588-603.

46. Malhi GS, Bassett D, Boyce P, Bryant R, Fitzgerald PB, Fritz K, et al. Royal Australian and New Zealand College of Psychiatrists clinical practice guidelines for mood disorders. Aust N Z J Psychiatry 2015:49:1087-1206.

47. Bauer M, Whybrow PC, Angst J, Versiani M, Möller HJ; World Federation of Societies Biological Psychiatry Task Force on Treatment Guidelines for Unipolar Depressive Disorders. World Federation of Societies of Biological Psychiatry (WFSBP) guidelines for biological treatment of unipolar depressive disorders, part 1: acute and continuation treatment of major depressive disorder. World J Biol Psychiatry 2002;3:5-43.

48. Bauer M, Whybrow PC, Angst J, Versiani M, Möller HJ; World 
Federation of Societies of Biological Psychiatry (WFSBF) Task Force on Treatment Guidelines for Unipolar Depressive Disorders. World Federation of Societies of Biological Psychiatry (WFSBP) guidelines for biological treatment of unipolar depressive disorders, part 2: maintenance treatment of major depressive disorder and treatment of chronic depressive disorders and subthreshold depressions. World I Biol Psychiatry 2002;3:69-86.

49. Bauer M, Bschor T, Pfennig A, Whybrow PC, Angst J, Versiani $\mathrm{M}$, et al. World Federation of Societies of Biological Psychiatry (WFSBP) guidelines for biological treatment of unipolar depressive disorders in primary care. World I Biol Psychiatry 2007;8:67-104.

50. Sachs GS, Printz DJ, Kahn DA, Carpenter D, Docherty JP. The expert consensus guideline series: medication treatment of bipolar disorder 2000. Postgrad Med 2000;Spec No:1-104.

51. Kriston L, von Wolff A, Westphal A, Hölzel LP, Härter M. Efficacy and acceptability of acute treatments for persistent depressive disorder: a network meta-analysis. Depress Anxiety 2014;31:621-630.

52. von Wolff A, Hölzel LP, Westphal A, Härter M, Kriston L. Selective serotonin reuptake inhibitors and tricyclic antidepressants in the acute treatment of chronic depression and dysthymia: a systematic review and meta-analysis. I Affect Disord 2013;144:7-15.

53. Tignol J, Stoker MJ, Dunbar GC. Paroxetine in the treatment of melancholia and severe depression. Int Clin Psychopharmacol 1992;7:91-94.

54. Entsuah AR, Rudolph RL, Chitra R. Effectiveness of venlafaxine treatment in a broad spectrum of depressed patients: a meta-analysis. Psychopharmacol Bull 1995;31:759-766.

55. Angst J, Stabl M. Efficacy of moclobemide in different patient groups: a meta-analysis of studies. Psychopharmacology (Berl) 1992;106 Suppl:S109-S113.

56. Perry PJ. Pharmacotherapy for major depression with melancholic features: relative efficacy of tricyclic versus selective serotonin reuptake inhibitor antidepressants. J Affect Disord 1996;39:1-6.

57. Anderson IM. Meta-analytical studies on new antidepressants. BrMed Bull 2001;57:161-178.

58. Gillman PK, Feinberg SS, Fochtmann LJ. Revitalizing monoamine oxidase inhibitors: a call for action. CNS Spectr 2020; 25:452-454.

59. Dickstein DP, Towbin KE, Van Der Veen JW, Rich BA, Brotman MA, Knopf L, et al. Randomized double-blind placebo-controlled trial of lithium in youths with severe mood dysregulation. J Child Adolesc Psychopharmacol 2009; 19:61-73.

60. Baweja R, Belin PJ, Humphrey HH, Babocsai L, Pariseau ME, Waschbusch DA, et al. The effectiveness and tolerability of central nervous system stimulants in school-age children with attention-deficit/hyperactivity disorder and disruptive mood dysregulation disorder across home and school. J Child AdolesC Psychopharmacol 2016;26:154-163.

61. Pan PY, Fu AT, Yeh CB. Aripiprazole/methy/phenidate combination in children and adolescents with disruptive mood dysregulation disorder and attention-deficit/hyperactivity disorder: an open-label study. J Child Adolesc Psychopharmacol 2018; 28:682-689.

62. Cipriani A, Zhou X, Del Giovane C, Hetrick SE, Qin B, Whittington $\mathrm{C}$, et al. Comparative efficacy and tolerability of antidepressants for major depressive disorder in children and adolescents: a network meta-analysis. Lancet 2016;388:881-890.

63. Wagner KD, Jonas J, Findling RL, Ventura D, Saikali K. A double-blind, randomized, placebo-controlled trial of escitalopram in the treatment of pediatric depression. I Am Acad Child Adolesc Psychiatry 2006;45:280-288.

64. Luxton R, Kyriakopoulos M. Depression in children and young people: identification and management NICE guidelines. Arch Dis Child Educ Pract Ed 2021. doi: 10.1136/archdischild2020-320020. [Epub ahead of print]

65. Ghaemi SN, Ko JY, Goodwin FK. “Cade's disease” and beyond: misdiagnosis, antidepressant use, and a proposed definition for bipolar spectrum disorder. Can J Psychiatry 2002; 47:125-134.

66. Hetrick SE, McKenzie JE, Cox GR, Simmons MB, Merry SN. Newer generation antidepressants for depressive disorders in children and adolescents. Cochrane Database Syst Rev 2012; 11:CD004851.

67. Konstantinou GN, Vigod SN, Mehta S, Daskalakis ZJ, Blumberger DM. "A systematic review of non-invasive neurostimulation for the treatment of depression during pregnancy". J Affect Disord 2020;272:259-268.

68. Damar U, Lee Kaye H, Smith NA, Pennell PB, Rotenberg A. Safety and tolerability of repetitive transcranial magnetic stimulation during pregnancy: a case report and literature review. J Clin Neurophysiol 2020;37:164-169.

69. Chou PH, Lin YF, Lu MK, Chang HA, Chu CS, Chang WH, et al. Personalization of repetitive transcranial magnetic stimulation for the treatment of major depressive disorder according to the existing psychiatric comorbidity. Clin Psychopharmacol Neurosci 2021;19:190-205. 